\title{
Insight into the influence of local streambed heterogeneity on hyporheic-zone flow characteristics
}

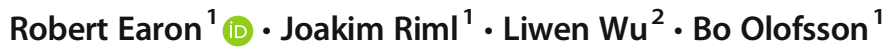 \\ Received: 5 March 2020 / Accepted: 13 September 2020 / Published online: 2 October 2020 \\ (C) The Author(s) 2020
}

\begin{abstract}
Interaction between surface water and groundwater plays a fundamental role in influencing aquatic chemistry, where hyporheic exchange processes, distribution of flow paths and residence times within the hyporheic zone will influence the transport of mass and energy in the surface-water/groundwater system. Geomorphological conditions greatly influence hyporheic exchange, and heterogeneities such as rocks and clay lenses will be a key factor for delineating the hyporheic zone. Electrical resistivity tomography (ERT) and ground-penetrating radar (GPR) were used to investigate the streambed along a 6.3-m-long reach in order to characterise geological layering and distinct features which may influence parameters such as hydraulic conductivity. Time-lapse ERT measurements taken during a tracer injection demonstrated that geological features at the meter-scale played a determining role for the hyporheic flow field. The penetration depth of the tracer into the streambed sediment displayed a variable spatial pattern in areas where the presence of highly resistive anomalies was detected. In areas with more homogeneous sediments, the penetration depth was much more uniformly distributed than observed in more heterogeneous sections, demonstrating that ERT can play a vital role in identifying critical hydraulic features that may influence hyporheic exchange processes. Reciprocal ERT measurements linked variability and thus uncertainty in the modelled resistivity to the spatial locations, which also demonstrated larger variability in the tracer penetration depth, likely due to local heterogeneity in the hydraulic conductivity field.
\end{abstract}

Keywords Heterogeneity · Electrical resistivity tomography · Tracer tests · Groundwater/surface-water relations · Geophysical methods

Electronic supplementary material The online version of this article (https://doi.org/10.1007/s10040-020-02244-5) contains supplementary material, which is available to authorized users.

Robert Earon

earon@kth.se

Joakim Riml

riml@kth.se

Liwen $\mathrm{Wu}$

liwen.wu@igb-berlin.de

Bo Olofsson

boolof@kth.se

1 Department of Sustainable Development, Environmental Science and Engineering, KTH Royal Institute of Technology, Teknikringen 10B, 10044 Stockholm, Sweden

2 Department of Ecohydrology, Leibniz-Institute of Freshwater Ecology and Inland Fisheries (IGB), Müggelseedamm 310, 12587 Berlin, Germany

\section{Introduction}

The interaction between surface water and groundwater is an important process in water resources management, influencing aquatic ecosystems (Findlay 1995; Brunke and Gonser 1997; Briggs et al. 2015) as well as water quality (Boulton et al. 1998; Boano et al. 2013; Lewandowski et al. 2019). Pressure-driven exchange of water and solutes across the water-streambed interface prolongs the solute residence time in the subsurface and increases the contact time between the sediments and solutes. Thus, hyporheic exchange directly influences transport and removal of both nutrients (Zarnetske et al. 2011; Azizian et al. 2017) and other types of contaminants (Findlay 1995; Krause et al. 2010; Riml et al. 2013). In areas with hyporheic processes which involve relatively large exchanged volumes over a short time interval, great variability in soil water chemistry can occur locally in the hyporheic zone which subsequently influences the chemical composition of both surface water and groundwater at larger scales (Acworth and Dasey 2003; Gomez-Velez et al. 2015). 
The physical extent of the hyporheic zone and the degree to which it varies temporally and spatially is often both highly variable and dependent on the in-situ conditions such as bedform geometry (Cardenas et al. 2004; Stonedahl et al. 2010; Boano et al. 2013; Mermillod-Blondin et al. 2015; Malenda et al. 2019), stream channel discharge (Maier and Howard 2011; Ward et al. 2010; Stonedahl et al. 2018; Wu et al. 2018) and regional groundwater flow patterns (Marzadri et al. 2016; Schmadel et al. 2016). Additionally, heterogeneities in both streambed topography and sediment composition influence the hyporheic exchange (Malenda et al. 2019). As such, even small heterogeneities in bed structure or hydraulic conductivity along a stream reach could have important implications for the exchange of energy and mass between surface water and the adjacent groundwater (Sawyer and Cardenas 2009; Bianchin et al. 2011; Tonina et al. 2016; Clémence et al. 2017; Liu and Chui 2017). Pore-scale heterogeneities in the streambed sediments have been shown to impact hydraulic behaviour, characterized by, e.g. the residence time distribution (Briggs et al. 2015; Fox et al. 2016) or permeability within the hyporheic zone (Zhou et al. 2013; Stonedahl et al. 2018), and can greatly influence interactions between groundwater and surface water where small heterogeneities such as stones or bathymetric irregularities can drastically change the flow field (Hester et al. 2009; Gomez-Velez et al. 2014; Zhang et al. 2017). Thus, in order to successfully describe an environmental system where the interactions between surface water and groundwater play an important role in transport and ecosystem processes, characterization of these interactions requires an understanding of the spatial nature of the hydraulic behaviour of the hyporheic zone (Ward et al. 2010).

Observations of hyporheic processes are usually performed through either point observations of chemical, hydraulic, or temperature gradients in vertical arrays across the stream-waterstreambed continuum (Wörman et al. 2012; Krause et al. 2013; Knapp et al. 2017) or through reach-scale assessments of the net reaction rates using either mass balance approaches (Fellows et al. 2001; Kunz et al. 2017) or tracer test evaluations (Riml et al. 2013; Haggerty et al. 2009). However, the spatial heterogeneity along the stream reach is difficult to assess using these approaches and demands other type of investigations. Recent application of geophysical methods for investigating the hyporheic zone is a promising approach where electrical resistivity imaging of natural (Acworth and Dasey 2003; Nyquist et al. 2008; Cardenas and Markowski 2011) or tracerinduced contrasts in electrical resistivity (Acworth and Dasey 2003; Nyquist et al. 2010; Ward et al. 2010, 2013b) have been successfully used to characterise the cross-sectional extent of the hyporheic zone but often lack the spatial resolution to investigate the effects of local heterogeneity on the spatial variability of hyporheic exchange processes. Investigations by Acworth and Dasey (2003) and Clémence et al. (2017) illustrate the influence of local variation on the vertical extent and temporal behaviour of the hyporheic zone. This is also highlighted by McLachlan et al. (2017) who noted that local measurements may not be representative of the actual typical conditions due to, e.g. local anomalous geological conditions, indicating that uncertainty introduced by study-site selection may limit the use of field observations in modelling endeavours. Moreover, it is difficult to accurately observe local-scale (e.g. 0.1-1 m) heterogeneity, with dubious tangible benefits, as doing so would demand the use of instrumentation which may potentially influence hyporheic processes (Ward et al. 2013a; McLachlan et al. 2017). Ward et al. (2013a) also noted difficulties in subsurface characterisation when using geophysical methods, where variations in the physical characteristics of the subsurface which influence superficial geophysical measurements may not be directly linked to the hydraulic parameters. Even the presence of measurement equipment may increase uncertainty, where equipment such as electrical resistivity tomography (ERT) electrodes (Bianchin et al. 2011) may influence other investigative methods such as ground-penetrating radar (GPR). However, combining the analysis of different geophysical methods and evaluating the results simultaneously could allow for a better understanding of the geological structures and physical nature of the hyporheic zone, through hypothesis testing of the various geophysical results against results from other methods. Further, reciprocal geoelectrical measurements have been shown to increase understanding of the spatial nature of potential errors and uncertainty in geophysics-based models (Zhou and Dahlin 2003).

The aim of this study was to explore the possibility of using a combination of geophysical and hydrological methods to assess the longitudinal spatial variability in streambed properties with a high spatial resolution and the subsequent effects on the delineation of the hyporheic zone in a small head-water stream. A driving hypothesis of this work is that local geological heterogeneities play an important role in the hyporheic exchanges in addition to the spatial variance and nonstable heterogeneity of the hydraulic conductivity field. The analyses were based on ERT measurements during a stream tracer test combined with post-tracer GPR measurements. Specific objectives include investigations of the local heterogeneities in the streambed, the spatial variability in the vertical extent of the hyporheic zone as well as differing spatial behaviour due to local anomalies, and the temporal response of penetration of the tracer in the streambed sediments seen in time-lapse ERT measurements.

\section{Materials and methods}

\section{Study site}

The Krycklan catchment is a 6,780-ha catchment to the north of Umeå, Sweden (Fig. 1). Several observations stations collecting meteorological, hydrological, and biogeochemical 


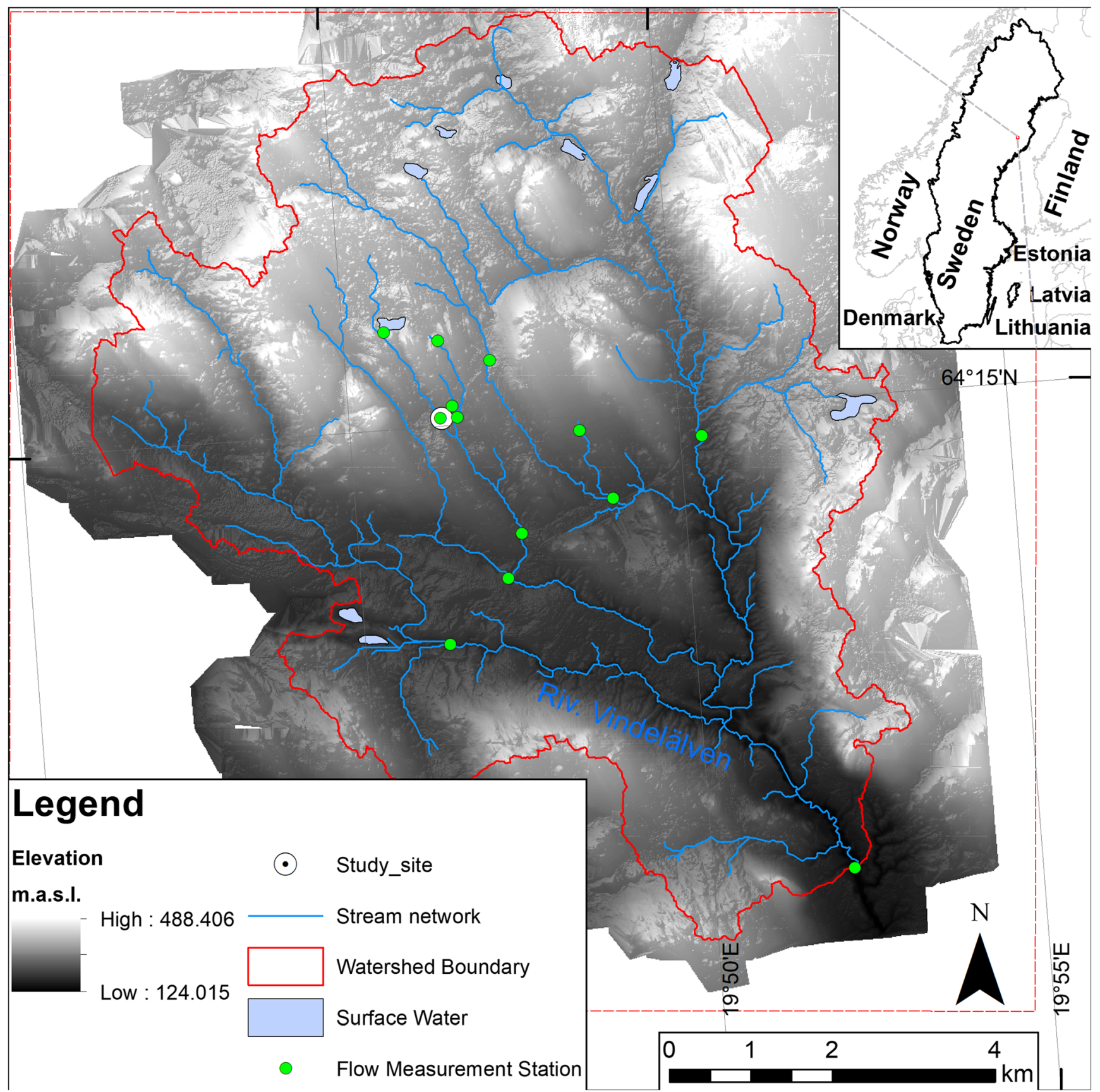

Fig. 1 Topographic map over the Krycklan Catchment and location of study site in Sweden (N713365, E731220 SWEREF99 TM)

data exist in the catchment and a great deal of research has been undertaken over the years (Öhman et al. 2009; Ågren et al. 2012; Laudon et al. 2013). The catchment is partially above the highest marine shoreline of the last period of glaciation and as such the terrain is comprised of variable wetland, till and boreal forest, with the most common soil types in the catchment being podsols. Precipitation in the region has an annual average of $600 \mathrm{~mm} /$ year and the region has an average temperature of $1{ }^{\circ} \mathrm{C}$ (Grabs et al. 2009). Vegetation in the area is mainly comprised of boreal forest comprised of Scots pine and Norway spruce (Laudon et al. 2013). The field experiment was conducted along a $6.3-\mathrm{m}$ reach in a stream located roughly in the middle of the catchment (Fig. 1). The stream reach (Fig. 2) was selected due to the proximity of a V-notch weir roughly $20 \mathrm{~m}$ upstream which allowed for accurate flow measurements during the study, as well as having physical characteristics which were assumed to be representative of the entire stream, with sections of both homogenous sandy sediments (Fig. 2a,b) and more heterogeneous, blocky sections with observed cobbles and hydraulic drops (Fig. 2b,c). The stream was roughly $1 \mathrm{~m}$ wide (bank to bank) with stream banks that were approximately $1 \mathrm{~m}$ high and an average water 
Fig. 2 The stream and single resistivity array aligned parallel to flow direction. Note that the streamflow was significantly higher at this time (ca. $Q=30 \mathrm{l} / \mathrm{s}$ ) compared to the time of ERT and GPR measurement (ca. $Q=61 / \mathrm{s}$ ). The section was observed to have an initial sandy reach $(\mathbf{a}-\mathbf{b})$ with some organic clay followed by a rockier section starting after around $4 \mathrm{~m}$ downstream (b) and continuing to the end of the measurement (c). Injection of sodium chloride tracer was carried out immediately upstream of the roughly $4 \mathrm{~m}$ long culvert

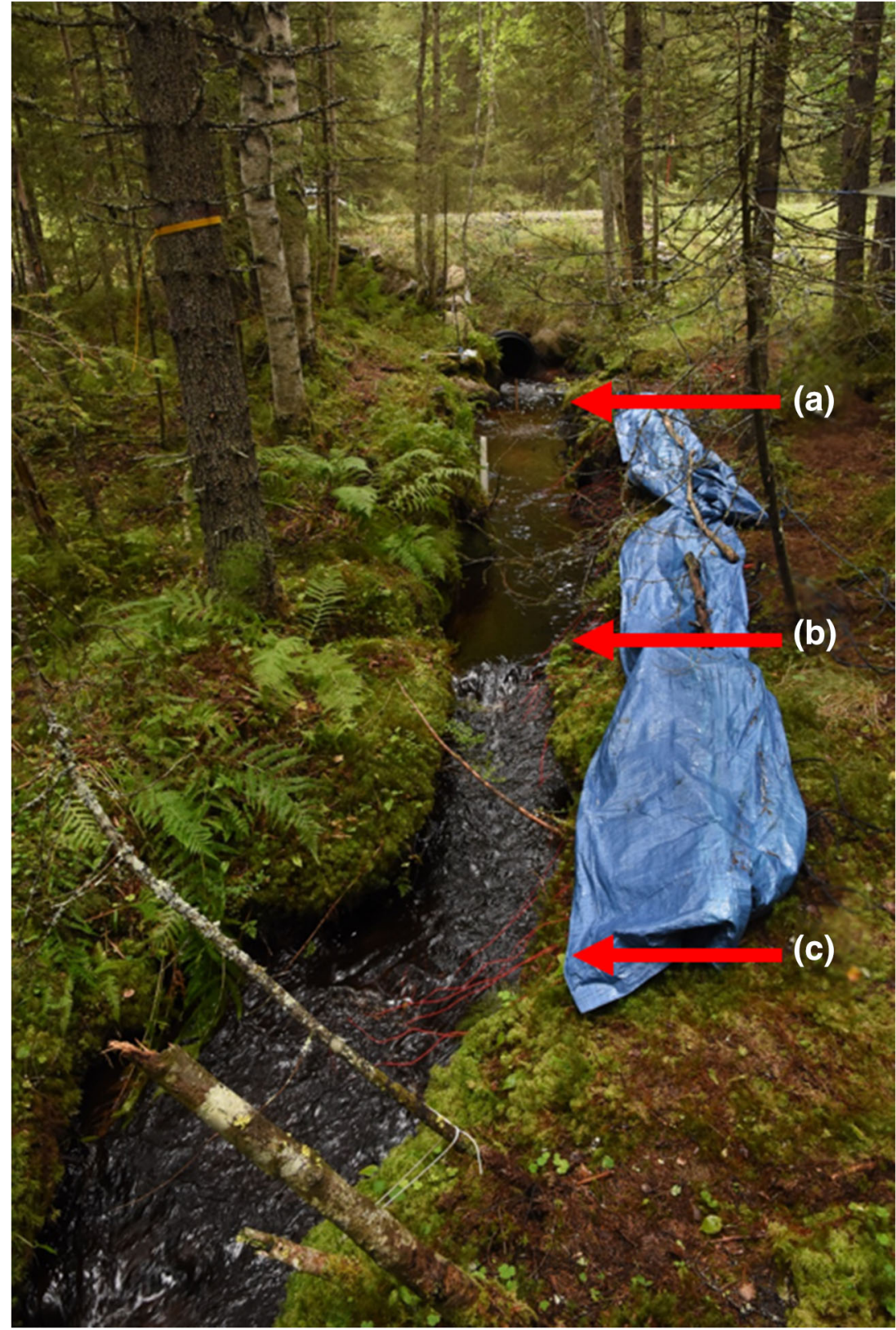

depth of approximately $0.2 \mathrm{~m}$. A hydraulic drop was located roughly midsection (Fig. 2b) due to the presence of cobbles. Soil samples were collected on 21 August 2017 at $x=0 \mathrm{~m}$ and $x=3 \mathrm{~m}$ along the reach at depths of $0-10 \mathrm{~cm}$ and $10-20 \mathrm{~cm}$, respectively, using a handheld sampling tube. In both samples the top decimetre was comprised of medium to fine grain sand $\left(0.06<\phi_{\text {grain }}<0.6 \mathrm{~mm}\right)$, with the lower decimetre comprised of sandy till with grain sizes from medium gravel $\left(6<\phi_{\text {grain }}<\right.$ $20 \mathrm{~mm}$ ) to silt $\left(\phi_{\text {grain }}<0.06 \mathrm{~mm}\right)$. Soil samples were dried for $24 \mathrm{~h}$ at $105^{\circ} \mathrm{C}$ and sieved by hand, with the fraction passing through a 2-mm sieve first mixed with a dispersion solution of $\mathrm{Na}_{4} \mathrm{P}_{2} \mathrm{O}_{7} \cdot 10 \mathrm{H}_{2} \mathrm{O}$ for more than $24 \mathrm{~h}$ and then analysed using the hydrometer method (Talme and Almén 1975) on 24-25 June 2020.

\section{Electrical resistivity measurements}

Electrical resistivity methods have a long history and wide range of applications in environmental modelling (Reynolds 2011; Clémence et al. 2017) particularly due to the method's frequent application in detecting subsurface resistivity changes likely due to ionic content of infiltrating water (Earon et al. 2012). However, the method can be prone to model error misrepresenting the actual resistivity of the subsurface due to equifinality in the inverse modelling process in heterogeneous environments (Earon et al. 2012) depending in part on the inversion modelling method used (Loke et al. 2003) and accuracy in electrode placement and orientation of the measurement lines (Zhou and Dahlin 2003). ERT measurements were carried out 
on 27 June 2017 using an ABEM Terrameter LS with an electrode spacing of $0.1 \mathrm{~m}$ along a $6.3 \mathrm{~m}$ roughly straight stretch of the stream in the estimated middle of the main flow path (Fig. 2). The electrodes were pushed into the sediments by hand until completely covered or carefully hammered using a small rubber mallet in order to avoid disturbing the natural sediments as much as possible. The electrodes were specially constructed for the experiment from stainless steel rods with a length of approximately $0.1 \mathrm{~m}$. Moreover, the electrodes were insulated in order to limit contact with the stream water and to maximize the current transmitted through the sediments and were constructed using insulated wire fastened under insulating rubber and silicon with a protective steel casing to allow for hammering into sediments (Fig. 3). Measurements were taken using a gradient array in order to maintain good vertical resolution (Reynolds 2011) with a total of 64 electrodes and the measurement time was approximately $45 \mathrm{~min}$ for one set of apparent resistivity measurements, a so-called pseudo-section. In total six pseudo-sections were collected over the tracer experiment's duration with fixed electrodes in the single array running parallel to the streams direction (see section 'Tracer and flow data') with two initial measurements taken immediately prior to the salt injection, with one measurement (start time roughly 15:30) similar (i.e. identical current direction) to those during the tracer injection followed by one reciprocal measurement (start time roughly 16:15) which was taken in order to gauge measurement error. Differences between the initial and reciprocal measurement are presented here as percent change from the initial to reciprocal where all subsequent measurements during the tracer test were collected in the same manner as the initial measurement. Electrical resistivity values of the saturated sediments were also estimated using Archie's Law (Oh et al. 2014):

$\rho_{\mathrm{t}}=a \rho_{\mathrm{f}} n^{-m}$

Where $\rho_{\mathrm{t}}$ is the electrical resistivity of the soil-fluid mixture, $a$ is a pore geometry or tortuosity coefficient, $\rho_{\mathrm{f}}$ is the electrical resistivity of the pore water, $m$ is a cementation exponent, and $n$ is porosity (estimated to be 0.2 ). Cementation exponent values have a wide range, but for sands they are in the range of 1.3-1.6 and clays are slightly higher at roughly 3 (Oh et al. 2014). The coefficients $a$ and $m$ were estimated based on Shah and Sing (2005) as 0.1 and 1.6, respectively.

The measurements were taken consecutively and as rapidly as the instrument and measurement protocol allowed, beginning simultaneously with the injection of the tracer and finally after the injection was terminated and the conductivity in the stream had returned to approximately initial conditions (Fig. 4). Once ERT measurements were collected, inverse modelling was carried out using the software Res2DInv (Geotomo Software 2018), in this study using a finiteelement inverse modelling routine to approximate a pseudosection which was mathematical compared to the pseudosection created during the data acquisition. Time lapse measurements were inverted using a finite-element method with the finest mesh possible in order to allow for better observation of vertical variation within the model where a greater number of finite element nodes allows for more variation in the mathematical model. A priority was placed on more vertical structures by setting the vertical to horizontal flatness ratio to 1.5 and a reduction of the effects of side blocks options were selected, the former in an attempt to account for discrete heterogeneities along the profile and the latter in order to reduce model variation near the boundaries (Cuthbert et al. 2009). Additionally, a robust constraint was selected which uses an absolute correction constraint rather than standard least-squares constraint in order to reduce the effect of noise on the model and allow for better representation of sharper model boundaries (i.e. rocks embedded in the sediments; Loke et al. 2003; Leroux and Dahlin 2006). Extreme values were removed ( $n=16$ of 1,392 ) from the raw data files through the selection of those data points which were more than three standard deviations from the mean. An additional inversion

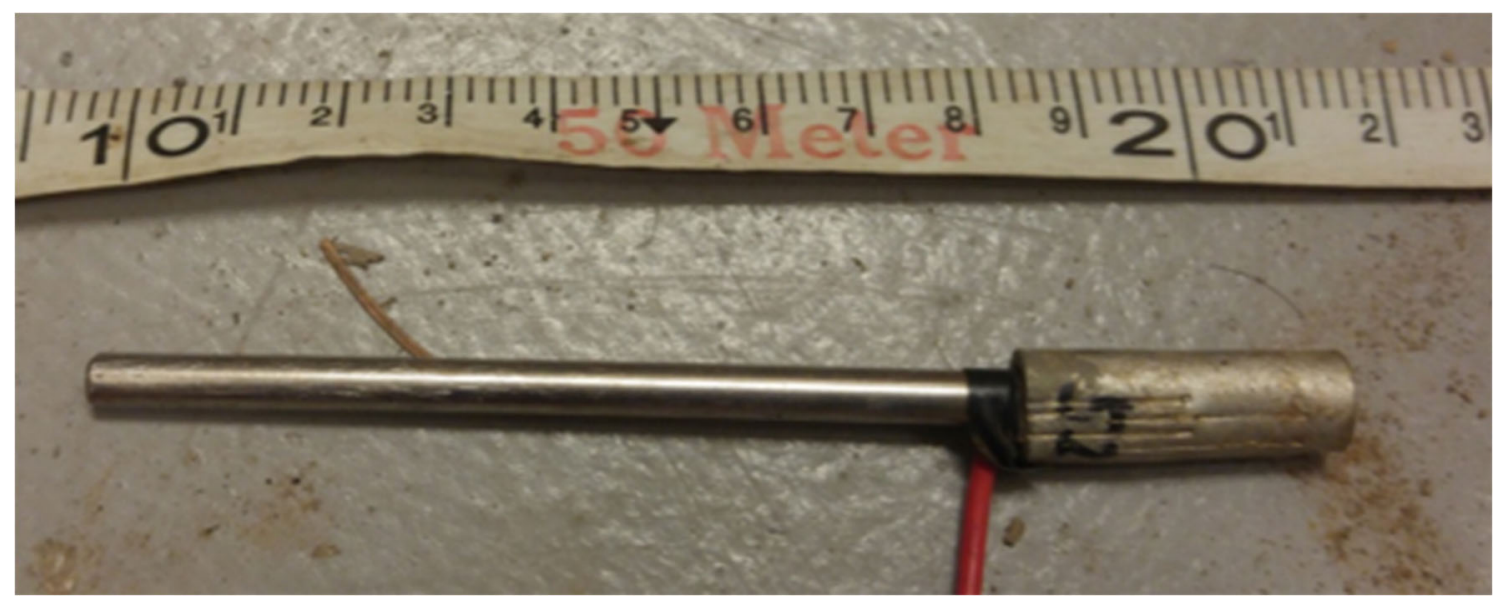

Fig. 3 Sample electrode constructed from stainless steel and insulated at the top portion where contact with surface water was most likely 

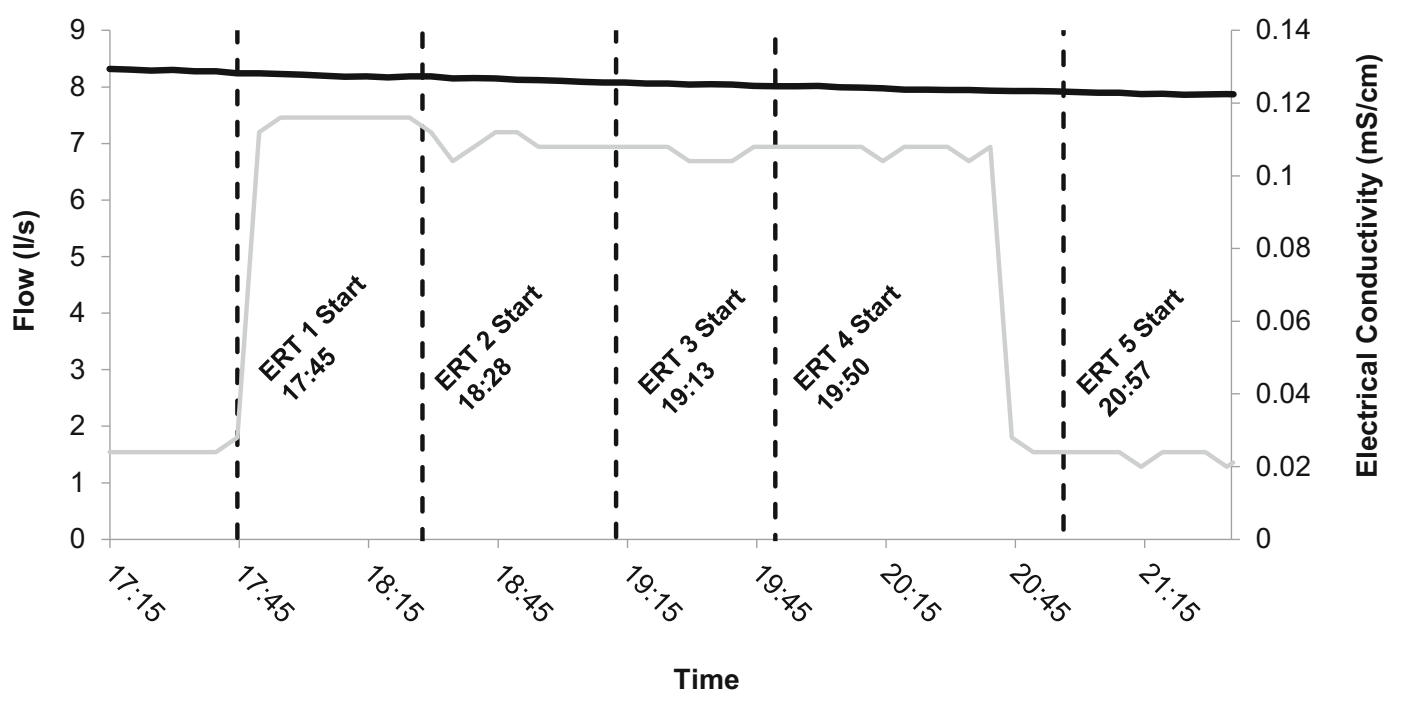

Flow _ - - ERT Measurement Start _ Electrical Conductivity (Upstream)

Fig. 4 Observed stream flow (black solid line) and electrical conductivity of the stream water (grey solid line) during the experiment. Vertical dashed lines indicate the start time of electrical resistivity measurement

was carried out with a fixed-resistivity $(100 \Omega \mathrm{m}) 0.1$-m-deep layer over the entire profile. This was done to compare inverse-model results with results assuming a larger portion of the electrical current was transmitted through the stream water with increased conductivity. Finally, reciprocal measurements were modelled using RES2DINV's time-lapse method with no time-lapse constraints against the initial measurement to investigate the impact of measurement orientation on modelled results. During measurements, one electrode was moved due to errors obtained while measuring. This electrode was located at $x=4.4 \mathrm{~m}$ in a section of the stream with more cobbles and errors were likely due to contact with the highly conductive stream water after introduction of the tracer. The electrode was moved laterally a few centimetres perpendicular to the measurement line in order to reduce measurement error (Zhou and Dahlin 2003). For the time-lapse inversions, the measurements using the electrode at $4.4 \mathrm{~m}$ were removed ( $n=110$ of 1,392), and a bed topography based on GPR measurements was assumed with an overlying water layer with a conductivity of $500 \Omega \mathrm{m}$ which was roughly the original conductivity of the stream water.

\section{Tracer and flow data}

The tracer used in the experiment was a $150 \mathrm{~g} / \mathrm{L}$ sodium chloride solution with an electrical conductivity of $81 \mathrm{mS} / \mathrm{cm}$. The tracer was prepared using stream water and salt in a container which was continuously stirred to obtain a well-mixed solution and was injected into the stream over a period of $3 \mathrm{~h}$ with an approximate pumping rate of $140 \mathrm{ml} / \mathrm{min}$ (Fig. 4). A submersible datalogger (CTD-Diver) with $22 \mathrm{~mm}$ diameter and ceramic housing was used to monitor the instream conductivity directly upstream of the resistivity measurements, which stabilized at $86-96 \Omega \mathrm{m}(0.104-0.116 \mathrm{mS} / \mathrm{cm})$ during the tracer plateau, compared with observed background resistivity levels of $416 \Omega \mathrm{m}(0.024 \mathrm{mS} / \mathrm{cm})$.

Stream flow data were recorded automatically as part of the Krycklan observation network using a V-notch weir at a permanent observation station roughly $20 \mathrm{~m}$ upstream of the measurement location. A slight decrease in stream flow over the duration of the experiment was seen, with flows at $8.3 \mathrm{~L} / \mathrm{s}$ at the start of the tracer injection and $7.9 \mathrm{~L} / \mathrm{s}$ at the termination of the experiment.

\section{Ground penetrating radar}

As electric permittivity can often be correlated to inherent conductivity of in-situ material and affects the reflection of radar waves (Reynolds 2011), GPR methods potentially could be used to identify sources of small-scale $(0-0.5 \mathrm{~m})$ heterogeneity in the hyporheic zone such as rocks or cobbles (Mermillod-Blondin et al. 2015; Malenda et al. 2019). A Malå 500-MHz GPR antenna was used to investigate the subsurface characteristics along the same measurement line as the ERT measurements. The instrument was rigged between two ropes, which were held and manually moved by an operator on either bank allowing the instrument to hang freely a couple of centimetres over the stream while measuring the subsurface. The instrument was anchored midstream by a small string at the start of the measurement line, which triggered the device to perform a measurement every $0.01 \mathrm{~m}$ as it was moved along the stream. Measurements were taken on the 21 August 2017, i.e. roughly 2 months after the tracer experiment, after the removal of the electrode array in order to 
minimize disturbance from the ERT electrodes. Additionally, measurements were made after a simulated flood event in August 2017 with flows exceeding $20 \mathrm{~L} / \mathrm{s}$, which may have altered the physical surface of the streambed through erosion of some sandy-silty sediment. Processing steps for analysing the radargram using the software Reflex2DQuick 2.0 included DC shift subtraction (63.7 ns), mean-subtraction (dewow) (2 ns), application of a linear gain (1.5) and exponential damping $(3 \mathrm{db} / \mathrm{m})$ and applying a five-trace running average.

\section{Results}

\section{ERT measurements}

Initial ERT measurements (i.e. prior to the tracer injection) indicated a prevalent heterogeneity in the streambed properties, with highly variable resistivity values both in horizontal and vertical directions (Fig. 5a,b). At shallow sediment depths up to roughly $0.3 \mathrm{~m}$, a less resistive layer was found with modelled values roughly $200-500 \Omega \mathrm{m}$, which would be reasonable values for a saturated silty-sand (Reynolds 2011). At deeper depths a layer with modelled resistivity in the range of 800 $1,000 \Omega \mathrm{m}$ was found, which would be consistent with saturated sand (Reynolds 2011). However, at localized positions along the reach higher resistivity values were observed, particularly in the downstream part of the reach $(x=4.4$ to $4.8 \mathrm{~m})$. These resistivity values ranged higher than $1,000-4,000 \Omega \mathrm{m}$ and were likely granitic blocks in the stream as opposed to saturated sand which would typically have resistivity values below $1,000 \Omega \mathrm{m}$ (Reynolds 2011). This assumption is consistent with field observations of a rockier streambed in the downstream section. The top layer with low resistivity values and with a depth of $0.2-0.3 \mathrm{~m}$ was consistently modelled from $x=0$ to $4 \mathrm{~m}$ in the measurement array with some heterogeneity evident throughout the section (Fig. 5a), possibly indicating a sandy layer with some pockets of finer material, possibly silt, and a few larger rocks. Downstream of this point $(x=4 \mathrm{~m})$ more frequent high resistivity, near-surface anomalies were found and the location of the low resistivity layer varied substantially in the $\mathrm{x}$ direction with vertical depths extending to $0.4 \mathrm{~m}$ at some locations while being close to zero at others. Electrical resistivity estimates of the sediments based on pretracer background stream resistivity measurements of $416 \Omega \mathrm{m}$ and Archie's law were $546 \Omega \mathrm{m}$.
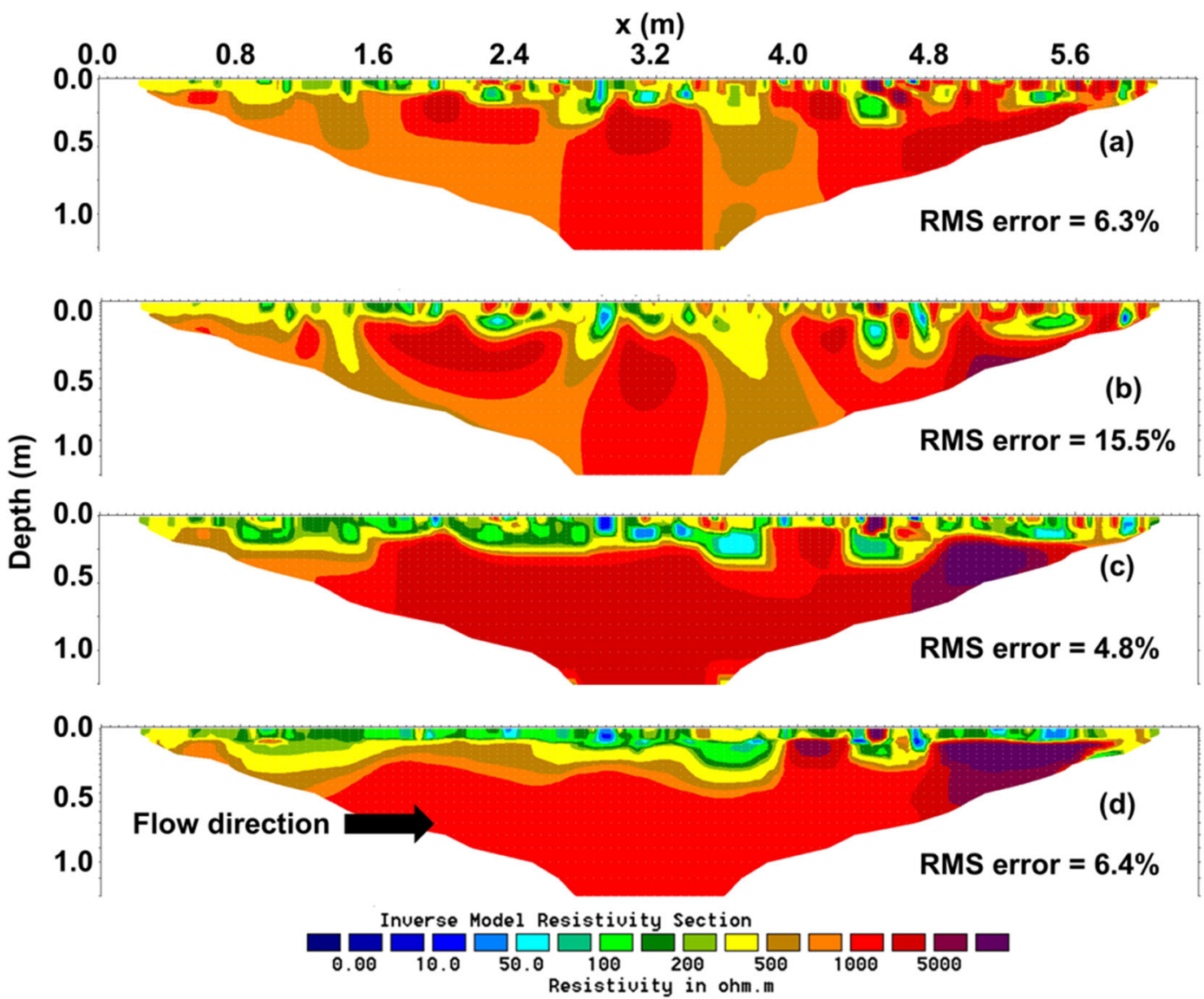

Fig. 5 Modelled resistivity values from a the initial ERT measurement of the approximate middle of the streambed prior to sodium chloride tracer addition, and $\mathbf{b}$ without the robust constraint. c Measurement taken approximately $130 \mathrm{~min}$ after introduction of the continuous tracer, and d the previous measurement adding an assumed top layer with a resistivity of $100 \Omega \mathrm{m}(0.1 \mathrm{mS} / \mathrm{cm})$ and a thickness across the entire section $0.1 \mathrm{~m}$. All models used seven inversion iterations 
During the tracer injection, when the conductivity of the stream water was increased, additional ERT measurements showed evidence of permeation of the tracer into the stream sediments (Fig. $5 \mathrm{c}$ ). Resistivity values in the top layer of the streambed dropped to values below $100-300 \Omega \mathrm{m}$ from 200 to $500 \Omega \mathrm{m}$, while highly resistive anomalies showed no change in position but varied slightly in modelled resistivity values, as did the deeper sediments (Fig. 5b). Estimating electrical resistivity using an assumed pore-water resistivity of $100 \Omega \mathrm{m}$ resulted in a bulk resistivity value of $131 \Omega \mathrm{m}$. This was likely a result of the modelling process, as more of the current would be directed through the highly conductive, tracer-saturated material at the top layer resulting in lower apparent resistivity values measured at deeper depths. Model results with an assumed conductive layer (Fig. 5d) showed similarity with initial inverse-model results, with slightly more shallow increases in conductivity from $x=1.6$ to $2.5 \mathrm{~m}, x=4.6 \mathrm{~m}$ and $x=4.8$ to $6 \mathrm{~m}$. All time-lapse ERT measurements taken during the tracer injection showed similar results to the initial postinjection measurement. During the tracer injection, a drop in resistivity appeared to follow the top layer and a distinct boundary emerged, here interpreted as the maximum depth of tracer penetration, i.e. the depth of the hyporheic zone which varied substantially along the investigated reach (Fig. 6). The time lapse resistivity measurements indicated that flow patterns of the tracer appear to penetrate to a maximum depth of $0.32 \mathrm{~m}$ from the streambed in the more homogeneous section of the measurement array $(x=0-4 \mathrm{~m})$. Around the position of a hydraulic drop in the stream the changes in resistivity were found up to a depth of $0.43 \mathrm{~m}$ (at $x=4.4 \mathrm{~m}$ ). In the rockier region a fairly homogeneous negative change in resistivity was seen in the more shallow depths of up to $0.2 \mathrm{~m}$. The final ERT measurement, starting roughly $30 \mathrm{~min}$ after the termination of the tracer injection, appears to be very similar to the initial preinjection measurement. Modelled differences between the initial (pretracer) and the final (after cessation of the tracer) ERT measurements were found to be mostly within $\pm 20 \%$, indicating that across the pseudo-section, the tracer has to a large extent been removed from the system. However, in the blockier areas $(x=1.8$ to $3.2 \mathrm{~m}$ and $x=4$ to $4.8 \mathrm{~m}$ ), isolated areas of lower resistivity values were still observed, which indicates that some of the tracer was still evident in these areas. Increases in resistivity were found in the inverse models, primarily in the greater depths during the tracer test (Fig. 6b-e) and in the final measurement (Fig. 6f) closer to the surface at areas corresponding to areas which were observed to have greater resistivity in initial measurements (Fig. 5a).

\section{Uncertainty in resistivity measurements}

Two reciprocal resistivity measurements taken before the tracer injection were compared, which resulted in both an average and median apparent-resistivity-measurement difference of $0.05 \%$ with a standard deviation (SD) of $0.35 \%$ for all measurements, and root mean square error (RMSE) of $0.35 \%$. Moreover, $89.8 \%$ of all apparent resistivity measurements had a difference within $\pm 1 \mathrm{SD}$ of the mean apparent-resistivity difference. Initial and reciprocal modelled differences indicated that $81.6 \%$ of all modelled values were within $\pm 1 \mathrm{SD}(0.79 \%)$ of the mean difference $(0.089 \%)$. A spatial investigation of the difference between the inverted reciprocal models demonstrated that the measurement uncertainty for each vertical section in the streambed varies along the measurement line (Fig. 7a). After $x=4 \mathrm{~m}$ along the measurement profile (Fig. 7a) the apparent resistivity variance becomes substantially more dispersed. This increase was likely due to the more heterogeneous streambed characteristics after $x=4 \mathrm{~m}$, where rockier sections were observed. Additionally, depth showed influence over the difference between reciprocal models (Fig. 7b) where the greatest differences between the models were found near the surface. The sign of the error had a negative tendency in the intermediate layers between 0.1 to $0.3 \mathrm{~m}$.

Additionally, to investigate the impact of moving one electrode, inversions were carried out on ERT 2 both with and without the electrode at $x=4.4 \mathrm{~m}$-Fig. S1 of the electronic supplementary material (ESM) - where only slight deviations between the models were seen in the magnitude of anomalies, but little difference was seen regarding the position of anomalies in the different models. Model sensitivity was also estimated by removing half and one-third of all electrodes (Fig. S2 of the ESM), and results showed that significant resolution was lost after removing even one third of the total number of electrodes.

\section{Ground penetrating radar measurements}

The GPR measurements indicated a noticeable heterogeneity in the streambed, where major reflections spatially coincided with areas with rockier streambed sections. This corresponded with the heterogeneity observed in the ERT measurements. Strong evidence of signal scattering, which can be associated with rockier sections, occurred from roughly $x=4-6 \mathrm{~m}$ along the profile (Fig. 8). In the initial 4-m stretch of the profile, the signals were more indicative of homogeneous sediments, corresponding with organic sediments which were observed in the field. There were also several layers evident from reflections in the upper $10 \mathrm{~ns}$ of the profile for $x=0-4 \mathrm{~m}$, downstream from which identification of individual layers became quite difficult due to the signal scattering. An estimate of the different layers identified from the GPR measurements was created by manually following distinct signals in the radargram and assuming a constant radar wave velocity within the layer (Reynolds 2011), resulting in the following stratigraphy - an initial reflection was assumed to be water with a velocity of $0.03 \mathrm{~m} / \mathrm{ns}$, with two following structures 
$x(m)$

3.2

4.0

4.8

5.6
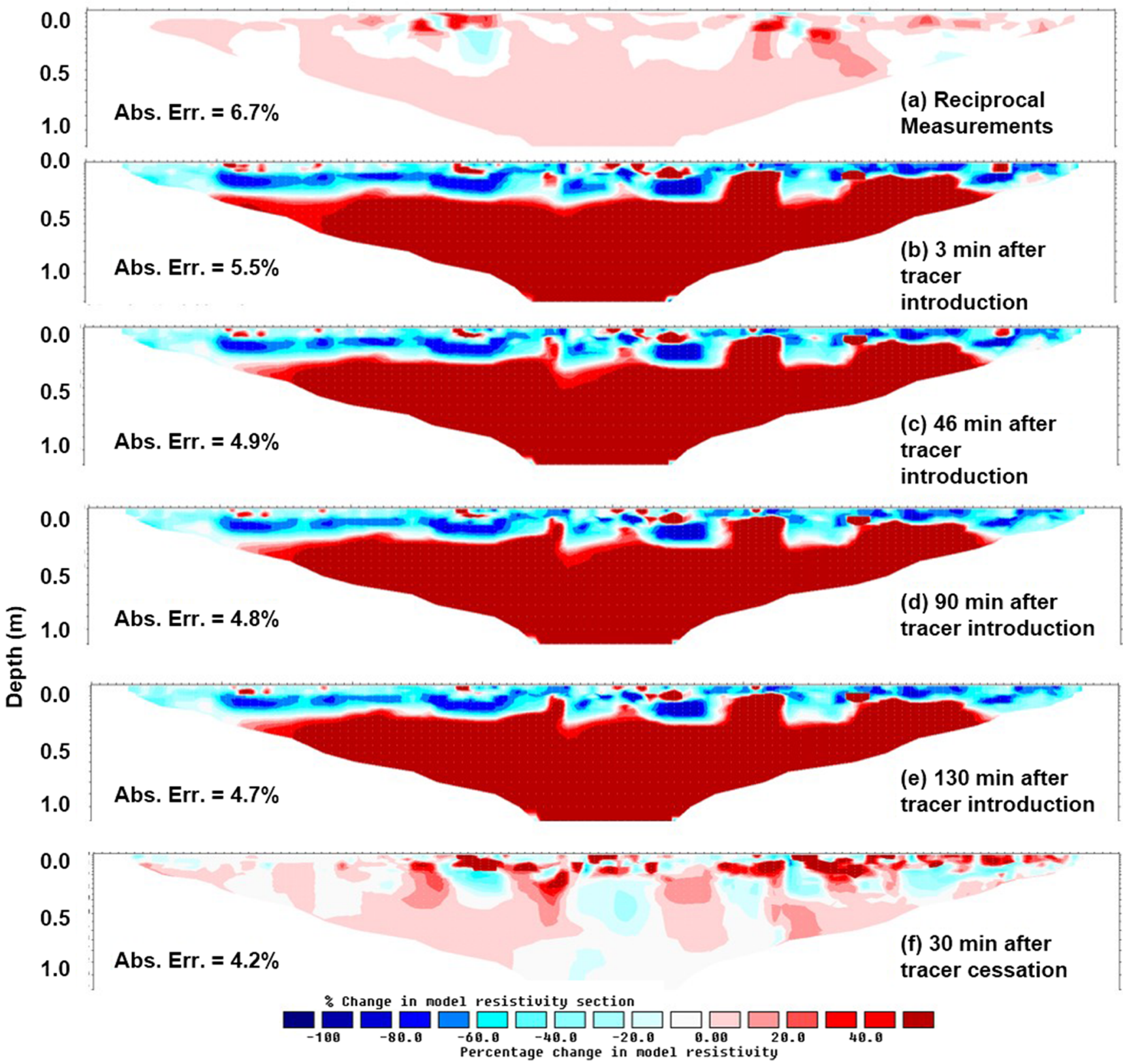

Fig. 6 Time-lapse resistivity measurements during the tracer test presenting the change in model resistivity compared to the background condition from the start of tracer injection. Sections represent the percent change between a reciprocal measurements prior to tracer introduction. Percent changes from the $\mathbf{b}$ initial, pre-injection measurement and measurements were initiated at approximately $3 \mathrm{~min}$ after introduction of tracer, c 46 min after introduction of tracer, d 90 min after introduction of tracer, e 130 min after introduction of tracer and $\mathbf{f} 30$ min after cessation of injection. The horizontal and vertical axes indicate longitudinal distance along the stream and depth, respectively. All models used seven inversion iterations

of $0.09 \mathrm{~m} / \mathrm{ns}$ (Fig. 8). These results agree with grain-size analyses (Fig. S3 of the ESM), where the upper decimetre at $x=$ $0 \mathrm{~m}$ and $3 \mathrm{~m}$ had significantly higher sand $(0.063-2 \mathrm{~mm})$ content, comprising 72 and $80 \%$ of the sample weight, respectively. In the deeper samples $(10-20 \mathrm{~cm})$, the sand content was 44 and $57 \%$ at $x=0$ and $3 \mathrm{~m}$, respectively. 

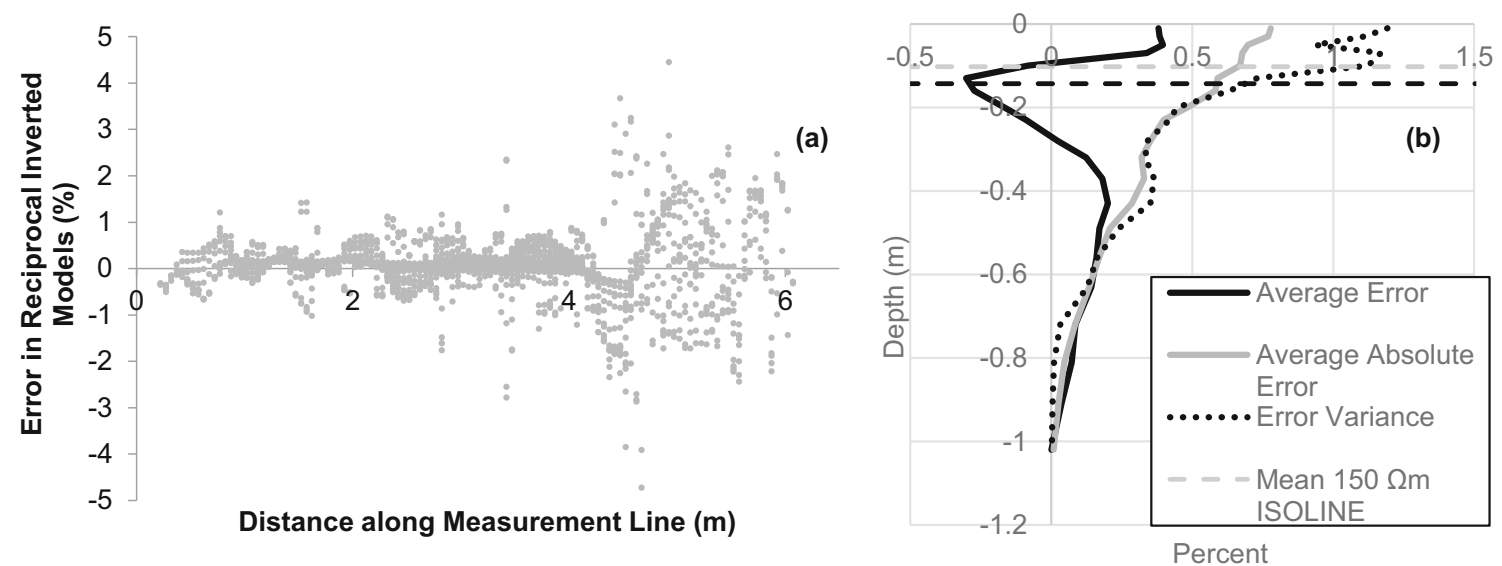

Fig. 7 a The percent difference in apparent electrical resistivity between the reciprocal models prior to tracer injection evaluated for all streambed depths at a given location. The numerical sign of the difference is

arbitrary. b The difference in apparent electrical resistivity between the reciprocal models as a function of streambed depth along with mean depths for 150 and $500 \Omega \mathrm{m}$ isolines from tracer plateau (ERT 4)

\section{Discussion}

\section{Initial measurements and conceptualization}

Streambed geomorphology exerts a strong control on the hyporheic exchange processes (Findlay 1995; Azizian et al. 2017) and spatial heterogeneities and local anomalies in sediment composition are thought to constrain the distributions in flow paths and residence times within the hyporheic zone (Mermillod-Blondin et al. 2015; Malenda et al. 2019). Here, a combination of geophysical and hydrological investigative methods was applied in a small boreal stream and the results emphasized the close connection between the spatial variability of local streambed structures, their hydraulic properties and the vertical extent of the hyporheic zone. The in-situ observations of the stream reach displayed several sections where

hydraulic conductivity in the sediments would likely vary and thus strongly affect the hyporheic exchange properties. The modelled resistivity values can be related to observed physical characteristics of the streambed, which allows for the identification of heterogeneities in the subsurface by way of inverse-modelled resistivity sections. Rocks and stones are likely the cause of near-surface resistive anomalies at $x=0.6$, 1.6, 2.4, 3 and 4-6 m (Fig. 6), which will strongly affect the hyporheic flow paths and makes the common assumption of well-behaved Tothonian flow cells used in hyporheic studies questionable. Irregular flow patterns around small-scale (i.e. stones and cobbles) heterogeneities have previously been shown in laboratory flumes (Fox et al. 2016; Stonedahl et al. 2018) or in numerical studies (Sawyer et al. 2011; Hester et al. 2013), but have not, to the authors' best knowledge, been identified for in-situ conditions in an active natural stream.

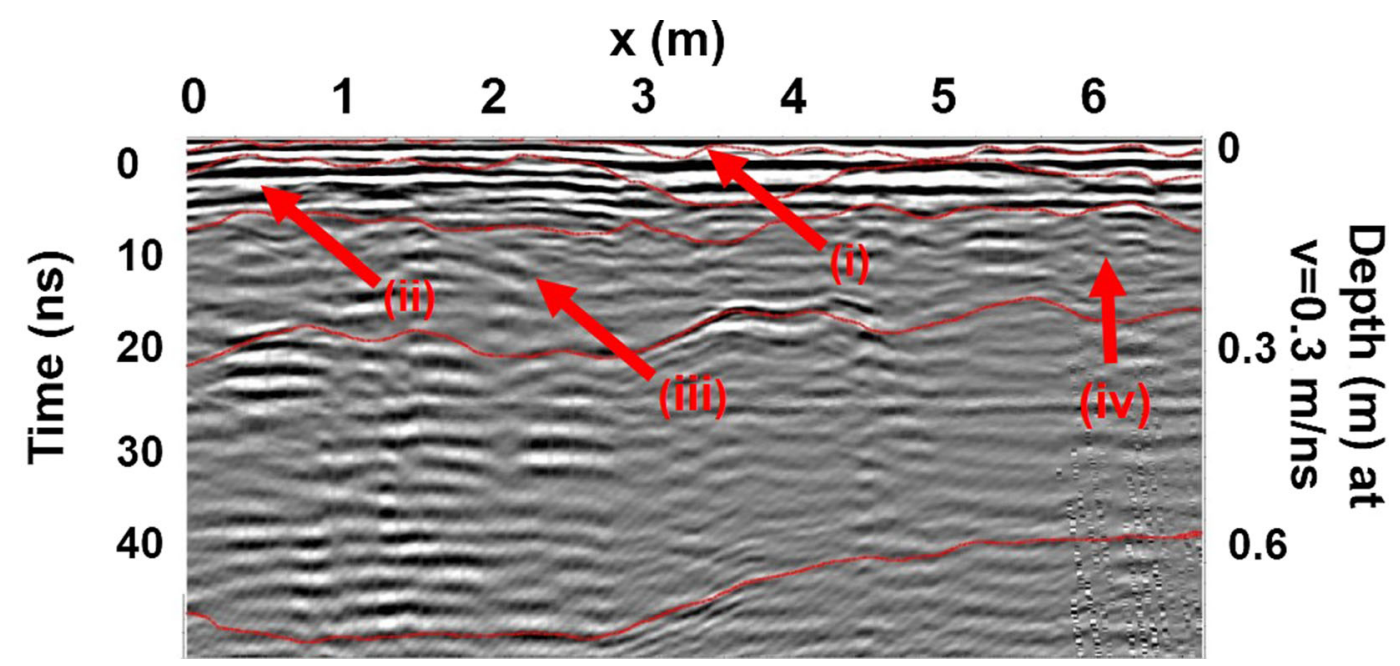

Fig. 8 Ground-penetrating-radar profile along the measurement line showing interpreted layers with two-way travel time and approximate signal depth given a homogeneous velocity of $0.03 \mathrm{~m} / \mathrm{ns}$. Approximate locations shown for (i) water surface, (ii) sandy sediments with low attenuation, (iii) silty-sandy sediments with higher attenuation and (iv) rockier section with more frequent discrete parabolic signal responses with apparent velocities of $0.09 \mathrm{~m} / \mathrm{ns}$. Note that due to the running average subtractions in the interpretation parabolas are difficult to display 


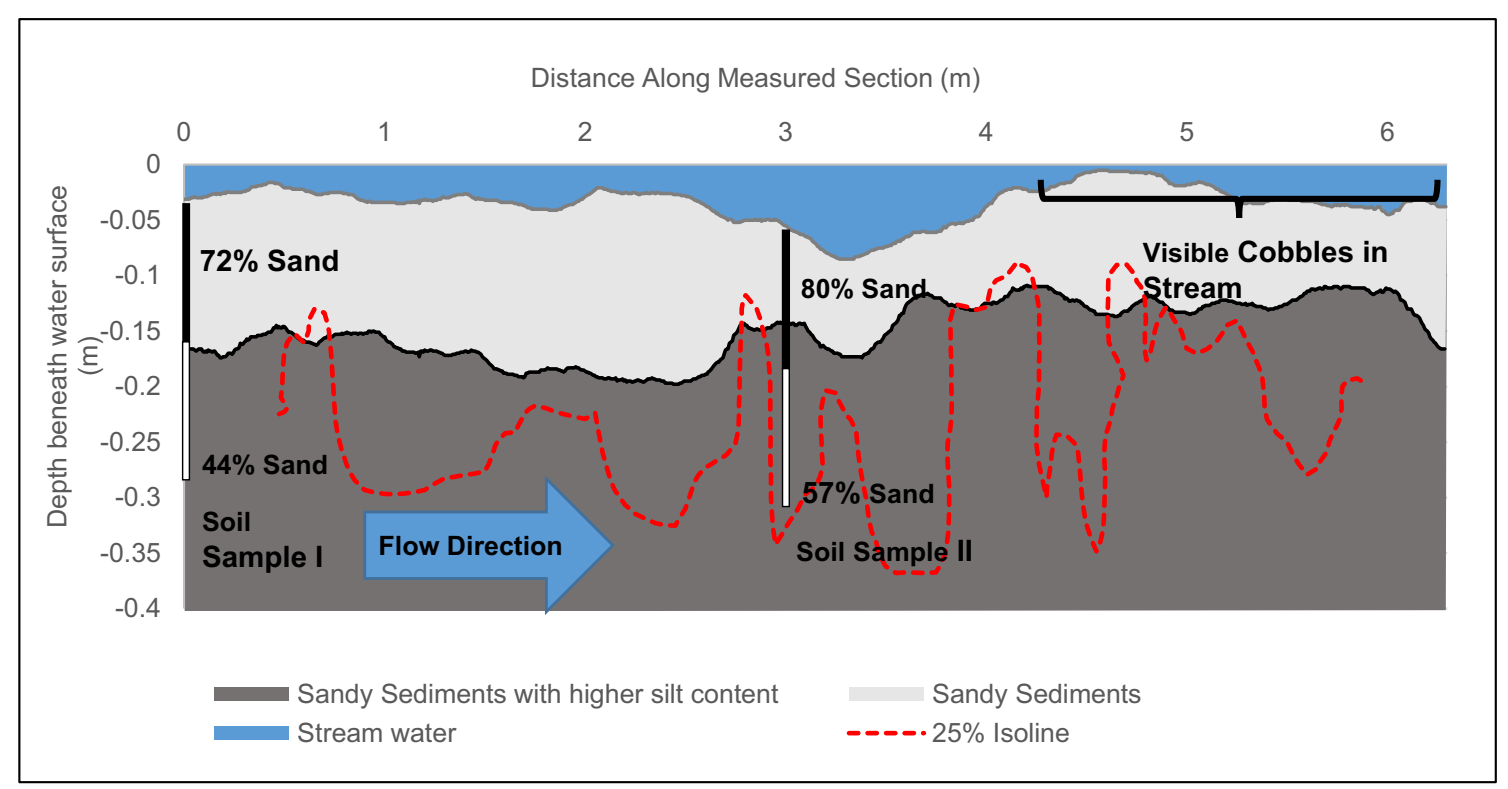

Fig. 9 Estimated layer boundaries identified from GPR measurements created by manually following distinct signals in the radargram. Interpreted layers shown are: sandy sediments with some finer grains showing little signal attenuation, sandy sediments with higher silt content showing more signal attenuation, and visible cobbles in the

As a direct consequence, the spatial variability in the occurrence of such structures will introduce uncertainty in estimates or models aiming to quantify surface-water/groundwater interaction, depending on the geometry and flow of the river or stream. Results indicate that observed rockier sections (Fig. 6, where $x$ is $4.4-4.8 \mathrm{~m}$, and Fig. 9) directly led to the largest modelled tracer penetration, while these sections also likely were the most uncertain in the inverse modelled. While regional models might not be strongly impacted by this scale of heterogeneity, smaller models investigating chemical or ecological processes may be influenced. Structures which may have meaningful influence on these processes may be missed entirely with even a small $(10 \mathrm{~cm})$ increase in electrode spacing (Fig. S2 of the ESM). Thus, in order to capture the spatial variability in the hyporheic flow field, particularly in postglacial regions with ubiquitous till coverage, a sufficiently high spatial resolution of the observations is needed, i.e. an electrode spacing and model resolution that reflects the scale of the governing processes and constraining factors that control the exchange fluxes.

The length of electrodes used in this study $(10 \mathrm{~cm})$ was equal to the electrode spacing which violates the assumption of electrodes as point sources. This violation was thought to be necessary in order to provide sufficient contact between the electrode and soil. Smaller, plate-formed electrodes could have been used but installing the electrodes may have disturbed the sediments more than the chosen method. Investigations of similar-scale tests (Clement and Moreau 2016) have shown that while the embedment, position and size of electrodes strongly influence measurements of stream with increased depth variation and more clear parabolas in the radargram, coinciding with observed section where more cobbles were present. The isoline corresponding with $25 \%$ resistivity decrease between the pretracer measurements and the ERT 4 inverse models is superimposed on the layers

apparent resistivity, these influences would be less than the order-of-magnitude differences in materials measured during the study. Additionally, no temperature correction was carried out during the inversion process. Thus, the changes in modelled resistivity during and after the tracer test are most likely more relevant to examine as opposed to the absolute accuracy of the resistivity models, the uncertainty of which is hard to ascertain given that no subsurface ground truth is available.

Different layers of streambed sediment were identifiable from the modelled section, which appeared to have had important influence over the results measured during the subsequent tracer injection. The differences in electrical resistivity and dielectric permittivity in the case of GPR, likely are indicative of different geological layers or anomalies. While they cannot be independently related to grain-sizes or soil types with certainty, the changes in modelled resistivity or reflections from a radargram can be linked with observations and conceptual models of the streambed. In particular, a geological layer with lower resistivity was likely present at around $0.2 \mathrm{~m}$ depth from $x$ range $0-2.5 \mathrm{~m}$ along the section (Figs. 5, 6 and 7), whereas this layer extended to depths corresponding to around $0.3-0.4 \mathrm{~m}$ below the streambed interface for the stream section between 2.4 and $4 \mathrm{~m}$. Further downstream this layer was less apparent due to the presence of more resistive anomalies (likely rocks) in the streambed interface but appears to continue up to around $0.3 \mathrm{~m}$ towards the end of the section. This conceptual understanding of the layering and heterogeneity was further strengthened by the apparent penetration of the tracer into the streambed sediment, which was evident 
during the tracer injection (Fig. 5b). This relationship between apparent different layers observed in pretracer ERT measurements and apparent tracer penetration (Fig. 9) supports the hypothesis that geophysical characterisation can give important insight into the heterogeneity of the hyporheic zone, and that this heterogeneity plays an important role in exchange processes. As the local soils are comprised primarily of glacial till, heterogeneity in the hyporheic zone would likely be heightened as a result of the variability in the grain-size distribution compared to regions with more geologically wellsorted soils. While different geological settings would almost certainly give rise to different measurement results, the differences in in-situ electrical resistivity may quite often coincide with differences in hydraulic conductivity between media (Reynolds 2011). Longitudinal characterisation using ERT methods could prove invaluable in identifying areas of low and high variability in permeability in the subsurface, highlighting the fragmentation of flow paths in the hyporheic zone and also be greatly beneficial in numerical model refinements.

The GPR results generally correspond with the ERT measurements, as more signal scattering was detected from 4 to $6 \mathrm{~m}$ along the stream section, which is indicative of blockier sections due to differences in permittivity between the rocks and surrounding sediments. However, layers were interpreted from the GPR measurements which were not as evident in the ERT sections; nevertheless, the main zone of increased conductivity identified in the ERT section also corresponded with the silty layer (Fig. 9) observed in the GPR profile at depths between 0.1 and $0.3 \mathrm{~m}$. This layer was found to have roughly the same depths along the profile, although the estimated depth in this case was based on the assigned velocity used during analysis. The combined geophysical methods gave a good indication of the structure and composition of the streambed sediment and were useful in delineating the hyporheic zone, something that has been shown previously, even when conductivity of the infiltrating water may not be vastly different, as in the case of coastal hyporheic zones, for example as seen in Bianchin et al. (2011).

\section{Time-lapse resistivity measurements}

In addition to providing the spatial distribution of apparent penetration depths of the highly conductive tracer, the timelapse modelling demonstrated that the tracer likely was influenced by preferential flow paths due to, for example, the presence of stones or sandy sediments, and that the arrival and exit of the tracer from the sediments occurred rapidly. The first ERT measurements taken after the tracer injection started (ERT 1, Fig. 4) were initiated immediately and took roughly 45 min to be completed; however, this measurement failed to capture the rising limb of the breakthrough curve which is indicative of quick solute transport paths within the stream sediments and the measurement was very similar to the other ERT measurements during the tracer test. Thus, the tracer appeared to infiltrate the hyporheic zone rather quickly, to depths up to $0.3-0.4 \mathrm{~m}$, through highly conductive pathways in distinct sections of the stream reach, while other sections likely with lower hydraulic conductivity restricted the hyporheic flow and almost no influence was seen from the tracer within the streambed. It should be restated, however, that smoothing during the inverse modelling process will likely exaggerate the apparent penetration depths. Additionally, the assumed conductivity of the water layer was initially set to be representative of the pretracer test's stream-water conductivity, which may further influence apparent tracer penetration. This apparent penetration of the tracer was largely similar to model results when a thin conductive layer was fixed in the upper portion of the model (Fig. 5d). The most notable difference in the models (Fig. 5c,d) was that the introduction of an assumed conductive layer appeared to elongate and flatten any conductivity anomalies, for example between $x=2.4$ and $3.2 \mathrm{~m}$ (Fig. $5 \mathrm{c}, \mathrm{d}$ ). The areas with the greatest penetration interpreted from increases in conductivity showed little to no change in depth. However, in the model with the more conductive layer (Fig. 5d), some near-surface anomalies, which were assumed to be associated with rocks and stones, were no longer identifiable $(x=5-6 \mathrm{~m})$ and which likely indicates a loss of near-surface resolution with this assumed conductive layer. A very rough estimate using the total measurement time and the apparent penetration depth yields a water velocity in the hyporheic zone on the scale of $10^{-4} \mathrm{~m} / \mathrm{s}$. Assuming Darcian flow, with a hydraulic conductivity in the sediments of $10^{-4} \mathrm{~m} / \mathrm{s}$ and a porosity of 0.2 , this would result in a specific discharge of $2 \times 10^{-5} \mathrm{~m} / \mathrm{s}$ and a hydraulic gradient of 0.2 , which would correspond with a $2-\mathrm{cm}$ change in hydraulic head over a distance of $10 \mathrm{~cm}$. Assuming a depth of $0.2 \mathrm{~m}$ and stream width of $0.3 \mathrm{~m}$, this also compares with an average stream velocity of roughly $0.12 \mathrm{~m} / \mathrm{s}$. These estimates are to be used as a basis for discussion, as more precise estimates would require much higher temporally resolved ERT measurements where a time step of 45 min fails to adequately capture the introduction of tracer into the sediments, detailed modelling and/or more precise estimates or porosity. Similarity between time-lapse measurements however indicates that while this type of investigation may not be suitable for shedding light on the transient nature of tracer introduction into the hyporheic zone, they may be appropriate for characterising small-scale heterogeneities in the flow paths in the sediments.

The apparent resistivity of the subsurface during the tracer injection plateau period (ERT 1 to ERT 4, Fig. 4) was roughly stable with less than $10 \%$ variation seen between measurements (Fig. 6), but the results demonstrated that the tracer following termination of the injection was removed rapidly (ERT 5, Figs. 4, 5 and 6). Thus, the general interpretation is that the residence times in the measured stream section may 
generally be consistently short, although large variability was found in the streambed composition and distribution of flow paths. General calculations of bulk resistivity using Archie's law and comparing modelled resistivity support the conclusion that tracer penetration occurs quite rapidly. Increases in resistivity seen in the time-lapse modelling (Fig. 6) are likely an artefact of the modelling process although such increases occasionally coincide with high-resistivity anomalies (Fig. 5); this is because, given the short time scale, the consistency of the stream water's background conductivity, and the absence of any artificially introduced resistive material, it is unlikely that any decreases in conductivity occurred during the experiment. As the tracer would almost certainly decrease the resistivity drastically in the top layers, this sharp boundary might be difficult for the modelling software to accurately capture, and some erroneously modelled positive resistivity changes occur in the deeper sections. Moreover, increases in resistivity seen in the final measurement (Fig. 6f) correspond roughly to the locations of many of the anomalies from the initial measurement (Fig. 5a), which likely represents rocks. This could be a result of some residual tracer present in the hydraulic pathways, which could result in some variability arising in the modelling iterations.

The interpretation of the hyporheic flow paths based on the ERT measurements during the tracer test correspond generally in shape with generic modelled hyporheic flow paths (Ward et al. 2013b; Tonina et al. 2016). However, local heterogeneities were shown to heavily impact the distribution of flow paths, indicating that the streambed structure plays a vital role for hyporheic exchange processes such as the physical extent and also, although not assessed here, the residence time within the hyporheic zone. Thus, the penetration depth of the tracer varied greatly along the stream reach. Sections which showed less variability in modelled resistivity values such as $0-2 \mathrm{~m}$ along the measured reach, were also found to have more shallow tracer penetration depths, predominantly around $0.2 \mathrm{~m}$ into the streambed (Figs. $4 \mathrm{~b}$ and $5 \mathrm{a}$ ). However, sections that showed higher levels of spatial variability in the modelled resistivity values also corresponded with the greatest penetration depths of the tracer. This was seen at 2.4, 3.6 and $4.4 \mathrm{~m}$ along the measured section (Fig. 6). This is likely due to heterogeneities in the streambed composition and topology such as stones and cobbles, creating steps in the surface-water profile that generate larger hydraulic gradients that induce the hyporheic exchange (Morén et al. 2017) and result in greater penetration depths, which is seen in time-lapse ERT measurements. Similar increases in hyporheic exchange have been shown for logs or other obstacles in the stream (Sawyer et al. 2011). While it was possible to observe many of these rocks and stones visually, there were several heterogeneities in the subsurface which were not visually apparent (i.e. buried rocks), notably the resistivity anomalies from 4.4 to $4.8 \mathrm{~m}$ along the stream reach. Additionally, at least some of the current transmitted during the ERT measurements was carried through the surface water rather than through the sediments, which could lead to erroneous modelling of very lowresistivity layers. However, the coincidence between the lowered-resistivity sections and the heterogeneities seen in the initial measurements indicate that surface features solely do not account for the behaviour of the tracer seen in the ERT measurements - for example, an abrupt deep penetration occurs at roughly $4.8 \mathrm{~m}$, as seen in the ERT profile (Fig. 6). This penetration corresponds with subsurface layering interpreted from GPR data, but not surface features such as stream water depth (Fig. 9), although when isolines corresponding to percent differences between ERT measurements are superimposed on the GPR layer model, the greatest apparent penetration appears to coincide with the deepest apparent stream depth at $x=3.2$ to $x=3.6 \mathrm{~m}$ (Fig. 9). The influence of subsurface structures on the apparent tracer penetration can be inferred from the variance in penetration corresponding with highly resistive anomalies, for example at $x=3.8$ to $x=4.8 \mathrm{~m}$ (Fig. 9). The selection of a $25 \%$ resistivity change may be slightly arbitrary, considering that any decrease in resistivity should be the result of the tracer. However, given the uncertainty inherent in inverse modelling and geophysics, this level was considered to be appropriate for illustrative purposes and further discussion. Additionally, the roughly constant flow of water in the stream would likely result in a more uniform layer with decreased resistivity than was seen in the time-lapse measurements. Moreover, the presence of areas showing slight decreased resistivity values after the termination of the tracer injection in areas corresponding to the sections with deepest assumed tracer penetration (Fig. 6) indicated that there was likely some tracer still evident in these sections during the final measurement. This also indicated that the measured anomalies were likely primarily a result of a spatial heterogeneity in streambed conductivity within the hyporheic zone rather than an effect of currents going through the surface water, since the tracer-laden stream water would have been flushed much more quickly.

\section{Spatial behaviour of uncertainty}

Variability between the two modelled reciprocal resistivity measurements also appears to be influenced by the heterogeneity of the streambed. As the granite cobbles observed in the stream would have resistivity values greatly and abruptly differing from the surrounding sediments by several orders of magnitude (Reynolds 2011), it is reasonable that the inversion modelling process have the highest errors and/or uncertainty (due to for example equifinality of models) over these sections. Lower resistivity changes in the time-lapse model results correspond with the conceptual model of the measured section created from the original ERT and GPR measurements. Greater uncertainty in these regions, seen in timelapse measurements taken during the tracer test, is then still acceptable, as the decreases in modelled resistivity adhere to 
the conceptual understanding of the tracer transport through the streambed. An increase in model variance in the $\mathrm{x}$ - and $\mathrm{z}$ directions between reciprocal resistivity measurements at a given location could therefore be strongly indicative of abrupt changes in composition and hydraulic characteristics of the sediments. The greatest differences seen in the reciprocal measurements appear to correspond exactly where the tracer was modelled to have the greatest penetration, likely due to presence of heterogeneities such as rocks, where drastic differences in electrical resistivity would be difficult to model. Absolute differences between the reciprocal models were quite low regardless of depth; however, the largest differences between the models were found in the shallowest regions, which is likely due to using volume-averaged modelling to represent nonlinear heterogeneous geological features. Theoretically, at larger depths, which correspond to a larger electrode spacing, small-scale heterogeneities cause less variation in the measurements. Conversely, at more shallow depths, which correspond to a smaller electrode spacing, these heterogeneities would occupy a larger relative volume and play a more important role in the model; thus, differences in measurements would likely be magnified in these smaller volumes. The switch in sign of the average difference in the model layers between 0.1 and $0.3 \mathrm{~m}$ (Fig. 7b) corresponds roughly to the layer found in the GPR profiles. This could be another indication of a layer with differing electrical, and likely hydraulic, characteristics as more of the current would be directed towards this more conductive layer when measuring in a particular direction depending on proximity of the active electrodes, and corresponds with GPR layer analyses.

The protocol used to collect the ERT measurement also had the electrode sets with the largest spacing first, which was related to the deepest measurements in the inversion modelling process where little relative change was seen. Given apparent rapid penetration of the tracer into the sediments and the time required per resistivity measurement, it would have been desirable to have the shallowest measurements occur first. However, the time between each individual measured electrode-set would still be quite large, so it is not certain that this would capture the rising stage of the tracer breakthrough curve via ERT measurements. The implication for this experiment was that some of the information relating to the rising stage of the tracer breakthrough curve was missed. In future studies, a better representation of the dynamic nature of the rising and falling stage of the tracer breakthrough curve might reduce uncertainties connected to the distribution of flow paths within the hyporheic zone.

\section{Conclusions}

Characterisation of small-scale heterogeneity of streambed sediments using geophysical measurements including ERT and GPR allows for a better understanding of flow paths which play an important role in determining the physical extent and nature of the hyporheic zone. Anomalies in the ERT measurements taken during the tracer injection coincided with observed streambed characteristics as well as GPR profiles, revealing an apparent high spatial variability in the distribution of hyporheic flow paths and providing the basis for geophysical investigations as a means for characterising the hyporheic zone at a high spatial resolution. Thus, longitudinal geophysical measurement can be used in the field to delineate and characterise the hyporheic zone at very high resolutions despite errors arising from electrode placement and shape. Investigations of this type could directly be used in applications aiming to investigate the effects and importance of groundwater/surface-water interactions and transport of mass and heat in the streambed sediments, such as numerical modelling of exchange processes. For quantitative approaches using, e.g. numerical models, ERT and GPR data could play a critical role in defining boundary conditions and localized areas or layers of differing permeability or porosity that constrain the hyporheic flow field as well as creating probability density functions of hydraulic parameters. Additionally, variance between reciprocal models gives evidence of the connection between these local anomalies in sediment composition and the physical extent of the hyporheic zone, where the spatial variance between reciprocal measurements could provide interesting insights regarding hydraulic parameters, which directly influences contaminant transport, ecological conditions or even large-scale hydrological fluxes.

Acknowledgements The authors thank the crew of the Krycklan Catchment Study (KCS) for their field assistance and acknowledge the suggestions made by Dr. Tao Cui and Dr. Audrey Sawyer as well as from an anonymous reviewer, which improved the quality of this work.

Funding Open access funding provided by Royal Institute of Technology. The authors acknowledge financial support from J. Gust. Richerts Stiftelse, grant number 2017-00364. Liwen Wu is funded by the European Union's Horizon 2020 research and innovation programme under the Marie Sklodowska-Curie grant agreement 641939 (HypoTRAIN) and from the German Research Foundation (DFG) within the Research Training Group Urban Water Interfaces (UWI; GRK 2032/1).

Open Access This article is licensed under a Creative Commons Attribution 4.0 International License, which permits use, sharing, adaptation, distribution and reproduction in any medium or format, as long as you give appropriate credit to the original author(s) and the source, provide a link to the Creative Commons licence, and indicate if changes were made. The images or other third party material in this article are included in the article's Creative Commons licence, unless indicated otherwise in a credit line to the material. If material is not included in the article's Creative Commons licence and your intended use is not permitted by statutory regulation or exceeds the permitted use, you will need to obtain permission directly from the copyright holder. To view a copy of this licence, visit http://creativecommons.org/licenses/by/4.0/. 


\section{References}

Acworth RI, Dasey GR (2003) Mapping of the hyporheic zone around a tidal creek using a combination of borehole logging, borehole electrical tomography and cross-creek electrical imaging, New South Wales, Australia. Hydrogeol J 11(3):368-377. https://doi.org/10. 1007/s10040-003-0258-4

Azizian M, Boano F, Cook PL, Detwiler RL, Rippy MA, Grant SB (2017) Ambient groundwater flow diminishes nitrate processing in the hyporheic zone of streams. Water Resour Res 53(5):3941-3967. https://doi.org/10.1002/2016WR020048

Ågren AM, Haei M, Blomqvist P, Nilsson MB, Laudon H (2012) Soil frost enhances stream dissolved organic carbon concentrations during episodic spring snow melt from boreal mires. Glob Chang Biol 18(6):1895-1903. https://doi.org/10.1111/j.1365-2486.2012.02666. $\mathrm{x}$

Bianchin MS, Smith L, Beckie RD (2011) Defining the hyporheic zone in a large tidally influenced river. J Hydrol 406(1-2):16-29. https:// doi.org/10.1016/j.jhydrol.2011.05.056

Boano F, Revelli R, Ridolfi L (2013) Modeling hyporheic exchange with unsteady stream discharge and bedform dynamics. Water Resour Res 49(7):4089-4099. https://doi.org/10.1002/wrcr.20322

Boulton AJ, Findlay S, Marmonier P, Stanley EH, Valett HM (1998) The functional significance of the hyporheic zone in streams and rivers. Annual Rev Ecol Syst 29:59-81. https://doi.org/10.1146/annurev. ecolsys.29.1.59

Briggs MA, Day-Lewis FD, Zarnetske JP, Harvey JW (2015) A physical explanation for the development of redox microzones in hyporheic flow. Geophys Res Lett 42(11):4402-4410. https://doi.org/10.1002/ 2015GL064200

Brunke M, Gonser R (1997) The ecological significance of exchange processes between rivers and groundwater. Freshw Biol 37(1):1-33

Cardenas MB, Markowski MS (2011) Geoelectrical imaging of hyporheic exchange and mixing of river water and groundwater in a large regulated river. Environ Sci Technol 45(4):1407-1411

Cardenas MB, Wilson JL, Zlotnik VA (2004) Impact of heterogeneity, bed forms, and stream curvature on subchannel hyporheic exchange. Water Resour Res 40(8). https://doi.org/10.1029/2004WR003008

Clémence H, Marc P, Véronique D, Toihir A (2017) Monitoring an artificial tracer test within streambed sediments with time lapse underwater 3D ERT. J Appl Geophys 139:158-169. https://doi.org/10. 1016/j.jappgeo.2017.02.003

Clement R, Moreau R (2016) How should an electrical resistivity tomography laboratory test cell be designed? Numerical investigation of error on electrical resistivity measurement. J Appl Geophys 127:4555. https://doi.org/10.1016/j.jappgeo.2016.02.008

Cuthbert MO, Mackay R, Tellam JH, Barker RD (2009) The use of electrical resistivity tomography in deriving local-scale models of recharge through superficial deposits. Q J Eng Geol Hydrogeol 42: 199-209. https://doi.org/10.1144/1470-9236/08-023

Earon R, Olofsson B, Renman G (2012) Initial effects of a new highway section on soil and groundwater. Water Air Soil Pollut 223(8):54135432. https://doi.org/10.1007/s11270-012-1290-6

Fellows CS, Valett MH, Dahm CN (2001) Whole-stream metabolism in two montane streams: contribution of the hyporheic zone. Limnol Oceanogr 46(3):523-531

Findlay S (1995) Importance of surface-subsurface exchange in stream ecosystems: the hyporheic zone. Limnol Oceanogr. 40(1):159-164. https://doi.org/10.4319/lo.1995.40.1.0159

Fox A, Laube G, Schmidt C, Fleckenstein JH, Arnon S (2016) The effect of losing and gaining flow conditions on hyporheic exchange in heterogeneous streambeds. Water Resour Res 52:7460-7477. https://doi.org/10.1002/2016WR018677
Geotomo Software (2018) Rapid 2-D resistivity and IP inversion using the least-squares method. http://www.geotomosoft.com/. Accessed 25 May 2018

Gomez-Velez JD, Krause S, Wilson JL (2014) Effect of low-permeability layers on spatial patterns of hyporheic exchange and groundwater upwelling. Water Resour Res 50(6):5196-5215. https://doi.org/10. 1002/2013WR015054

Gomez-Velez JD, Harvey JW, Cardenas MB, Kiel B (2015) Denitrification in the Mississippi River network controlled by flow through river bedforms. Nat Geosci 8(12):941-945. https://doi.org/ 10.1038/ngeo2567

Grabs T, Seibert J, Bishop K, Laudon H (2009) Modelling spatial patterns of saturated areas: a comparison of the topographic wetness index and a dynamic distributed model. J Hydrol 373(1-2):15-23. https:// doi.org/10.1016/j.jhydrol.2009.03.031

Haggerty R, Martí E, Argerich A, von Schiller D, Grimm NB (2009) Resazurin as a "smart" tracer for quantifying metabolically active transient storage in stream ecosystems. J Geophys Res 114(G3). https://doi.org/10.1029/2008JG000942

Hester ET, Doyle MW, Poole GC (2009) The influence of in-stream structures on summer water temperatures via induced hyporheic exchange. Limnol Oceanogr 54(1):355-367. https://doi.org/10. 4319/10.2009.54.1.0355

Hester ET, Young KI, Widdowson MA (2013) Mixing of surface and groundwater induced by riverbed dunes: implications for hyporheic zone definitions and pollutant reactions. Water Resour Res 49: 5221-5237. https://doi.org/10.1002/wrcr.20399

Knapp JLA, González-Pinzón R, Drummond JD, Larsen LG, Cirpka OA, Harvey JW (2017) Tracer-based characterization of hyporheic exchange and benthic biolayers in streams. Water Resour Res 53(2): $1575-1594$

Krause S, Hannah DM, Fleckenstein JH, Heppell CM, Kaeser D, Pickup R, Pinay G, Robertson AL, Wood PJ (2010) Inter-disciplinary perspectives on processes in the hyporheic zone. Ecohydrology 4(4): 481-499. https://doi.org/10.1002/eco.176

Krause S, Tecklenburg C, Munz M, Naden E (2013) Streambed nitrogen cycling beyond the hyporheic zone: flow controls on horizontal patterns and depth distribution of nitrate and dissolved oxygen in the upwelling groundwater of a lowland river. J Geophys Res Biogeosci 118:54-67. https://doi.org/10.1029/2012JG002122

Kunz JV, Hensley R, Brase L, Borchardt D, Rode M (2017) High frequency measurements of reach scale nitrogen uptake in a fourth order river with contrasting hydromorphology and variable water chemistry (Weiße Elster, Germany). Water Resour Res 53:328343. https://doi.org/10.1002/2016WR019355

Laudon H, Taberman I, Ågren A, Futter M, Ottosson Löfvenius M, Bishop K (2013) The Krycklan catchment study-a flagship infrastructure for hydrology, biogeochemistry, and climate research in the boreal landscape. Water Resour Res 49(10):7154-7158. https://doi.org/10.1002/wrcr.20520

Leroux V, Dahlin T (2006) Time-lapse resistivity investigations for imaging saltwater transport in glaciofluvial deposits. Environ Geol 49: 347-358. https://doi.org/10.1007/s00254-005-0070-7

Lewandowski J, Arnon S, Banks E, Batelaan O, Betterle A, Broecker T, Coll C, Drummond JD, Gaona Garcia J, Galloway J, Gomez-Velez J, Grabowski RC, Herzog SP, Hinkelmann R, Höhne A, Hollender J, Horn MA, Jaeger A, Krause S, Löchner Prats A, Magliozzi C, Meinikmann K, Mojarrad BB, Mueller BM, Peralta-Maraver I, Popp AL, Posselt M, Putschew A, Radke M, Raza M, Riml J, Robertson A, Rutere C, Schaper JL, Schirmer M, Schulz H, Shanafield M, Singh T, Ward AS, Wolke P, Wörman A, Wu L (2019) Is the Hyporheic zone relevant beyond the scientific community? Water 11(11):2230. https://doi.org/10.3390/w11112230

Liu S, Chui TFM (2017) Impacts of streambed heterogeneity and anisotropy on residence time of hyporheic zone. Groundwater 35(1). https://doi.org/10.1111/gwat.12589 
Loke MH, Acworth R, Dahlin T (2003) A comparison of smooth and blocky inversion methods in 2D electrical imaging surveys. Explor Geophys 34(3):182-187. https://doi.org/10.1071/EG03182

Maier HS, Howard KWF (2011) Influence of oscillating flow on hyporheic zone development. Groundwater 49(6):830-844. https:// doi.org/10.1111/j.1745-6584.2010.00794.x

Malenda HF, Sutfin NA, Guryan G, Stauffer S, Rowland JC, Williams KH, Singha K (2019) From grain to floodplain: evaluating heterogeneity of floodplain hydrostratigraphy using sedimentology, geophysics, and remote sensing. Earth Surf Process Landforms 44(9): 1799-1815. https://doi.org/10.1002/esp.4613

Marzadri A, Tonina D, Bellin A, Valli A (2016) Mixing interfaces, fluxes, residence times and redox conditions of the hyporheic zones induced by dune-like bedforms and ambient groundwater flow. Adv Water Resour 88:139-151. https://doi.org/10.1016/j.advwatres. 2015.12.014

McLachlan PJ, Chambers JE, Uhlemann SS, Binley A (2017) Geophysical characterisation of the groundwater-surface water interface. Adv Water Resour 109:302-319. https://doi.org/10.1016/j. advwatres.2017.09.016

Mermillod-Blondin F, Winiarski T, Foulquier A, Perrissin A, Marmonier $P$ (2015) Links between sediment structures and ecological processes in the hyporheic zone: ground-penetrating radar as a non-invasive tool to detect subsurface biologically active zones. Ecohydrol 8(4): 626-641. https://doi.org/10.1002/eco.1530

Morén I, Wörman A, Riml J (2017) Design of remediation actions for nutrient mitigation in the hyporheic zone. Water Resour Res 53: 8872-8899. https://doi.org/10.1002/2016WR020127

Nyquist JE, Freyer PA, Toran L (2008) Stream bottom resistivity tomography to map groundwater discharge. Groundwater 46(4):561-569. https://doi.org/10.1111/j.1745-6584.2008.00432.x

Nyquist JE, Toran L, Fang AC, Ryan RJ, Rosenberry DO (2010) Tracking tracer breakthrough in the hyporheic zone using timelapse DC resistivity, Crabby Creek, Pennsylvania. In: Proceedings of the 23rd Annual Symposium on the Application of Geophysics to Engineering and Environmental Problems (SAGEEP) Keystone, CO April 11-15, 2010. https://doi.org/10.4133/1.3445534

Oh TM, Cho GC, Changho L (2014) Effect of soil mineralogy and porewater chemistry on the electrical resistivity of saturated soils. J Geotech Geoenviron Eng 140(11). https://doi.org/10.1061/(ASCE) GT.1943-5606.0001175

Öhman K, Seibert J, Laudon H (2009) An approach for including consideration of stream water dissolved organic carbon in long term forest planning. AMBIO: J Human Environ 38(7):387-394

Reynolds JM (2011) An introduction to applied and environmental geophysics, 2nd edn. Wiley-Blackwell, London

Riml J, Wörman A, Kunkel U, Radke M (2013) Evaluating the fate of six common pharmaceuticals using a reactive transport model: insights from a stream tracer test. Sci Tot Environ 458:344-354. https://doi. org/10.1016/j.scitotenv.2013.03.077

Sawyer AH, Cardenas MB (2009) Hyporheic flow and residence time distributions in heterogeneous cross-bedded sediment. Water Resour Res 45(8). https://doi.org/10.1029/2008WR007632

Sawyer AH, Cardenas MB, Buttles J (2011) Hyporheic exchange due to channel-spanning logs. Water Resour Res 47(8). https://doi.org/10. 1029/2011WR010484
Schmadel NM, Ward AS, Lowry CS, Malzone JM (2016) Hyporheic exchange controlled by dynamic hydrologic boundary conditions. Geophys Res Lett 43(9):4408-4417. https://doi.org/10.1002/ 2016GL068286

Shah PH, Singh DN (2005) Generalized Archie's law for estimation of soil electrical conductivity. J ASTM Int 2(5). https://doi.org/10. 1520/JAI13087

Stonedahl SH, Harvey JW, Wörman A, Salehin M, Packman AI (2010) A multiscale model for integrating hyporheic exchange from ripples to meanders. Water Resour Res 46(12). https://doi.org/10.1029/ 2009WR008865

Stonedahl SH, Sawyer AH, Stonedahl F, Reiter C, Gibson C (2018) Effect of heterogeneous sediment distributions on hyporheic flow in physical and numerical models. Groundwater 56(6):934-946. https://doi.org/10.1111/gwat.12632

Talme O, Almén KE (1975) Jordartsanalys: Laboratorieanvisningar, Del 1. University of Stockholm, Stockholm

Tonina D, de Barros FPJ, Marzadi A, Bellin A (2016) Does streambed heterogeneity matter for hyporheic residence time distribution in sand-bedded streams? Adv Water Resour 96:120-126. https://doi. org/10.1016/j.advwatres.2016.07.009

Ward AS, Gooseff MN, Singa K (2010) Imaging hyporheic zone solute transport using electrical resistivity. Hydrol Process 24(7):948-953. https://doi.org/10.1002/hyp.7672

Ward AS, Gooseff MN, Singha K (2013a) How does subsurface characterization affect simulations of hyporheic exchange? Groundwater 51(1):14-28. https://doi.org/10.1111/j.1745-6584.2012.00911.x

Ward AS, Gooseff MN, Voltz TJ, Fitzgerald M, Singha K, Zarnetske JP (2013b) How does rapidly changing discharge during storm events affect transient storage and channel water balance in a headwater mountain stream? Water Resour Res 49:5473-5486. https://doi.org/ $10.1002 /$ wrcr. 20434

Wu L, Singh T, Gomez-Velez JD, Nutzmann G, Wörman A, Krause S, Lewandowski J (2018) Impact of dynamically changing discharge on hyporheic exchange processes under gaining and losing groundwater conditions. Water Resour Res 54(12). https://doi.org/10.1029/ 2018WR023185

Wörman A, Riml J, Schmadel N, Neilson BT, Bottacin-Busolin A, Heavilin JE (2012) Spectral scaling of heat fluxes in streambed sediments. Geophys Res Lett 39(23). https://doi.org/10.1029/ 2012GL053922

Zarnetske JP, Haggerty R, Wondzell SM, Baker MA (2011) Dynamics of nitrate production and removal as a function of residence time in the hyporheic zone. J Geophys Res 116(G1). https://doi.org/10.1029/ 2010JG001356

Zhang Y, Wang JL, Yang P (2017) Movement of lateral hyporheic flow between stream and groundwater. Sci China Earth Sci 60(11):20332040. https://doi.org/10.1007/s11430-016-9103-9

Zhou B, Dahlin T (2003) Properties and effects of measurement errors on 2D resistivity imaging Near Surface Geophys 1(3):105-117. https:// doi.org/10.3997/1873-0604.2003001

Zhou Y, Ritzi RW, Soltanian MR, Dominic DF (2013) The influence of streambed heterogeneity on hyporheic flow in gravelly rivers. Groundwater. https://doi.org/10.1111/gwat.12048 